\title{
Circadian Rhythm Characteristics in Mood Disorders: Comparison among Bipolar I Disorder, Bipolar II Disorder and Recurrent Major Depressive Disorder
}

\author{
Jae Kyung Chung ${ }^{1}$, Kyu Young Lee ${ }^{1}$, Se Hyun Kim², Eui-Joong Kim', Seong Hoon Jeong ${ }^{3}$, Hee Yeon Jung ${ }^{4}$, \\ Jung-Eun Choi ${ }^{5}$, Yong Min Ahn ${ }^{6}$, Yong Sik Kim ${ }^{7}$, Eun-Jeong Joo \\ ${ }^{1}$ Department of Neuropsychiatry, Eulji General Hospital, Eulji University School of Medicine, Seoul, ${ }^{2}$ Institute of Human Behavioral Medicine, \\ Medical Research Institute, Seoul National University, Seoul, ${ }^{3}$ Department of Neuropsychiatry, Eulji University Hospital, Eulji University \\ School of Medicine, Daejeon, ${ }^{4}$ Department of Psychiatry, SMG-SNU Boramae Medical Center, Seoul National University College of \\ Medicine, Seoul, ${ }^{5}$ Department of Psychiatry, Seoul Metropolitan EunPyeong Hospital, Seoul, ${ }^{6}$ Department of Psychiatry, Seoul National \\ University Hospital, Seoul National University College of Medicine, Seoul, ${ }^{7}$ Department of Neuropsychiatry, Dongguk University International \\ Hospital, Dongguk University Medical School, Goyang, Korea
}

Objective: Morningness/eveningness (M/E) is a stable characteristic of individuals. Circadian rhythms are altered in episodes of mood disorder. Mood disorder patients were more evening-type than normal population. In this study, we compared the characteristics of M/E among the 257 patients with bipolar I disorder (BPD1), bipolar II disorder (BPD2) and major depressive disorder, recurrent (MDDR).

Methods: M/E was evaluated using the Korean version of the composite scale of morningness (CS). Factor analysis was done to extract specific elements of circadian rhythm (morning preference, morning alertness, and evening tiredness). The total score and scores for factors and individual items of CS were compared in order to evaluate differences among the three different diagnostic groups. Factor scores of CS were different among the diagnostic groups.

Results: BPD1 subjects had a higher score for evening tiredness than BPD2 subjects ( $p=0.060)$, and BPD1 subjects had a significantly higher score for morning alertness than subjects with MDDR ( $p=0.034)$. This difference was even more profound for the representative item scores of each factor; item 2 of CS for evening tiredness (BPD1>BPD2, $p=0.007$ ) and item 5 of CS for morning alertness (BPD1>MDDR, $p=0.002$ ). Total score of CS were not different among 3 diagnostic groups.

Conclusion: Circadian rhythm characteristics measured by CS were different among BPD1, BPD2, and MDDR. BPD2 showed more eveningness than BPD1. MDDR showed less morningness than BPD1. CS would be a reasonable endophenotype associated with mood disorders. More studies with large sample size of mood disorders on M/E are warranted.

KEY WORDS: Bipolar I disorder; Bipolar II disorder; Composite scale; Major depressive disorder; Chronotype.

\section{INTRODUCTION}

The regular rhythm of night and day regulates our life, as it does for most living organisms. Individual differences in the phases of human activity have long been considered and a continuum can be placed from morningness to eveningness. Diurnal preference is believed to be related to the phase of endogenous circadian rhythms. ${ }^{1)}$ Morningness/eveningness $(\mathrm{M} / \mathrm{E})$ variation measures are

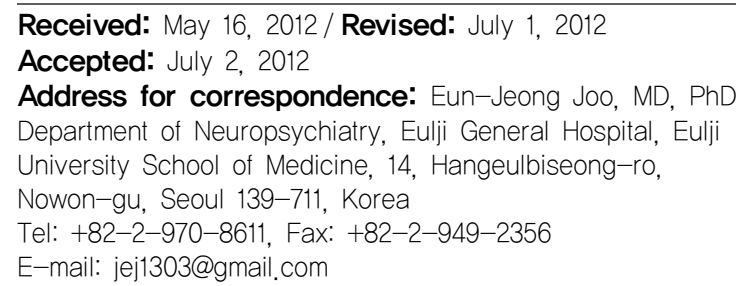

associated with individual differences in the timing of physiological circadian rhythms in cardiovascular stress levels and core body temperature, as well as behavioral rhythms related to eating, exercise and performance. ${ }^{2-4)}$ Morningness and eveningness are heritable ${ }^{5)}$ and associated with circadian gene polymorphisms. ${ }^{6,7)}$ Recent genetic findings have demonstrated that some molecular mechanisms control circadian rhythms. ${ }^{8)}$

Circadian rhythm hypotheses have been prominent in the explanation of major depressive disorder (MDD) and bipolar disorder (BPD). Various evidence provides support for an association between circadian rhythm dysfunction and mood disorder. Various phases of mood disorder (depressed, manic, episode prodrome, and interepisode periods) are associated with circadian rhythm abnormalities. Patients in the manic phase generally have a de- 
creased need for sleep, and insomnia and hypersomnia are both commonly found in depressive patients. ${ }^{9)}$ Sleep disturbance is a common prodromal symptom of mania and is also seen in the prodrome of depression. ${ }^{10)}$ A relationship between depression and circadian phase delay has been suggested. ${ }^{11)}$ There seems to be a predisposition for circadian rhythm alteration in mood disorder patients. Sleep disturbances and instability of circadian rhythm continue when mood disorder patients are not acutely ill. ${ }^{12-14)}$ Since disruptions to circadian rhythms have been found among patients with MDD and BPD, interventions stabilizing circadian rhythms is recognized as therapeutic in consensus treatments of MDD and BPD. ${ }^{15-17)}$ Delayed circadian phase of melatonin secretion has been reported in euthymic bipolar and unipolar patients. ${ }^{18)}$

It has been hypothesized that abnormalities in the molecular clock underlie the development of mood disorders. ${ }^{19-21)}$ Genes are considered to constitute an important etiologic factor in both mood disorders and circadian rhythm. Circadian gene polymorphisms are associated with symptoms of mood disorder in preclinical and human studies. ${ }^{22-24)}$ Although endophenotypes involved in mood disorder are largely unknown, $\mathrm{M} / \mathrm{E}$ appears to be a good candidate.

The studies involving college students and adolescents have suggested that individuals with higher self-rated depression scores are more likely to be evening types. ${ }^{25,26)}$ Patients with MDD have been also reported to be significantly more evening type than controls. ${ }^{27)}$ Bipolar I disorder (BPD1) cases were more evening type than community based control individuals and cases with schizophrenia/schizoaffective disorder cases. ${ }^{28)}$ Other studies on BPD patients also suggest that BPD cases tended to be more evening-type than subjects in control groups and there were no significant differences in $\mathrm{M} / \mathrm{E}$ scores between BPD1 or bipolar II disorder (BPD2) cases. ${ }^{29)} \mathrm{A}$ study in Korea showed that adults with BPD1 had more evening patterns when compared with controls. ${ }^{30)}$ Thus, replicated evidence consistent with circadian phase alterations in MDD and BPD is now available. However, to our knowledge, no study has evaluated the differences in $\mathrm{M} / \mathrm{E}$ variation among BPD1, BPD2 and MDD individuals.

BPD2 had more chronic and recurrent depressive episodes, while BPD1 had more severe episodes. ${ }^{31)}$ Because BPD2 does not seem to be more episodic than BPD1, we assumed that BPD1 patients and BPD2 patients would have different circadian rhythm characteristics. We considered the possibility that patients who had experienced only a single episode of MDD differed from those with
MDD, recurrent (MDDR) in terms of circadian rhythm features. To get a more homogenous group for this study, we selected an MDDR group of patients with chronic and recurrent depressive episodes. In the present study, we compared the characteristics of M/E among BPD1, BPD2 and MDDR. The total score as well as factor scores and individual items of the $\mathrm{M} / \mathrm{E}$ scale were analyzed in order to assess possible differences among mood disorders.

\section{METHODS}

\section{Subjects}

A total of 257 patients (male $=77$, female $=180$ ), with mood disorders participated in this study. These patients were recruited from the Eulji General Hospital and several psychiatric clinics in Seoul. There were 106 subjects with BPD1, 43 with BPD2, and 108 with MDDR; to be considered as eligible for inclusion in the study. The MDDR patient had to have experienced two or more separate major depressive episodes. Diagnoses were assigned to each patient according to the criteria in the Diagnostic and Statistical Manual of Mental Disorders, 4th edition (DSM-IV). At least 2 different psychiatrists reviewed and discussed the psychiatric data, which included psychiatric interviews and Korean version of Mini International Neuropsychiatric Interview (K-MINI) ${ }^{32)}$ conducted by research nurses, and medical records. After reviewing the data, the psychiatrists reached a consensus on the final diagnoses of each patient. Subjects with a history of any kind of substance use, organic brain syndrome, or any general medical condition possibly manifesting as psychiatric symptoms were excluded from this study. All subjects participating in this study signed a written informed consent. The study protocol was approved by the ethics committees of both Eulji General Hospital and Seoul National University Hospital.

\section{Measurement of Morningness/Eveningness}

$\mathrm{M} / \mathrm{E}$ was measured by pen and paper self-report questionnaires. $^{2)}$ The composite scale of morningness $(\mathrm{CSM})$ is a 13-item questionnaire which assesses individual differences in the time of day a person prefers to carry out various activities, and classifies people as morning-type or evening-type. ${ }^{33)}$ Previous studies have demonstrated good test-retest reliability and adequate external validity for the CSM. ${ }^{34,35)}$ The CSM has been translated into Korean and the Korean translation (i.e., CS) has been verified to have acceptable psychometric properties. ${ }^{36,37)}$ Three items are scored on a five-point scale from 1 to 5 , 
and the remaining 10 items are scored on a four-point scale, from 1 to 4 . Higher scores indicate morning preference. Patients were asked to complete the CS and all the patients were done.

\section{Statistical Methods}

\section{Factor analysis of CS}

A principal component analysis (PCA) was conducted on the CS 13 items. The Kaiser-Meyer-Olkin measure (KMO) verified the sampling adequacy for the analysis $(\mathrm{KMO}=0.86)$. Barlett test of sphericity indicated that correlations between items were sufficiently large for PCA $(p<0.001)$. An initial analysis was run to obtain eigenvalues for each component in the data. We used Kaiser's criterion of retaining factors with eigenvalues greater than 1 . Since factors were correlated with one another, promax rotation was performed to maximize the loading of each variable on one of the extracted factors and to minimize the loading on all other factors. SPSS-K ver. 12.0 (SPSS Inc., Chicago, IL, USA) was used for the analysis.

\section{Comparisons among three diagnostic groups}

Three different groups of mood disorders were compared for circadian rhythm characteristics. The three groups were BPD1, BPD2, and MDDR. First, we compared the age at interview and the age at onset of each diagnostic group using analysis of variance (ANOVA). Post hoc comparisons were performed with Tukey honestly significant difference tests (Tukey HSD) using SPSS-K 12.0. Since the mean age at interview was significantly different among patient groups and age is well known to be significantly correlated with CS scores, analysis of covariance (ANCOVA) was used to compare circadian rhythm characteristics among the three diagnostic groups
(BPD1, BPD2, MDDR) using age as a covariate. Post hoc comparisons were then performed to reveal any significant differences among the diagnostic groups. We analyzed the males and the females separately, since gender difference has been found in many aspects of mood disorder. The CS total score, factor scores, and individual item scores were investigated as circadian rhythm characteristics. All of the above analyses were performed with SPSS-K 12.0.

\section{RESULTS}

The mean age at interview among those with BPD1 was 38 years; it was 32 years for those with BPD2, and 56 years for those with MDDR. The groups differed significantly in terms of age at interview (ANOVA test, $p<$ 0.01 ). Those with MDDR were significantly older than the other groups. The mean age at onset among those with BPD1 was 27 years; it was 24 years for those with BPD2, and 46 years for those with MDDR. The groups differed significantly in terms of the age at onset (ANOVA test, $p<0.01)$. The age of onset was significantly higher in those with MDDR than in the other groups. There was a preponderance of females in our sample $(70.04 \%$ of the all subjects, Table 1).

The factor analysis on our sample found three factors structure for CS. They were morning preference, morning alertness and evening tiredness. These three factors explained $58.5 \%$ of the total variance of the CS total score; the main portion $(37.54 \%)$ of variance was explained by the morning preference factor (Table 2). Morning preference was correlated with morning alertness and evening tiredness. However, morning alertness was relatively less correlated with evening tiredness.

Total scores of CS were significantly correlated with the age at interview in all the subjects (Pearson's $r=0.293$,

Table 1. Age at interview and age at onset of subjects (years)

\begin{tabular}{|c|c|c|c|c|c|c|}
\hline & \multicolumn{2}{|c|}{ BPDI } & \multicolumn{2}{|c|}{ BPD2 } & \multicolumn{2}{|c|}{ MDDR } \\
\hline & $\mathrm{N}$ & Mean (SD) & $\mathrm{N}$ & Mean (SD) & $\mathrm{N}$ & Mean (SD) \\
\hline Total & 106 & & 43 & & 108 & \\
\hline Age & & 37.75 (12.95) & & $32.09(12.40)$ & & $55.73(11.68)$ \\
\hline Age at onset & & $26.74(11.86)$ & & 24.08 (11.39) & & $45.60(14.05)$ \\
\hline Male & 39 & & 18 & & 20 & \\
\hline Age & & $39.95(13.42)$ & & $31.00(14.54)$ & & 57.45 (16.59) \\
\hline Age at onset & & $27.53(12.97)$ & & $23.20(11.74)$ & & $48.50(17.24)$ \\
\hline Female & 67 & & 25 & & 88 & \\
\hline Age & & $36.48(12.61)$ & & $32.88(10.86)$ & & $55.34(10.33)$ \\
\hline Age at onset & & $26.27(11.24)$ & & 24.71 (11.38) & & 45.67 (10.89) \\
\hline
\end{tabular}

BPD1, bipolar I disorder; BPD2, bipolar II disorder; MDDR, major depressive disorder, recurrent; SD, standard deviation. 
Table 2. CS items and 3 factors

\begin{tabular}{|c|c|c|c|c|}
\hline $\begin{array}{c}\text { CS } \\
\text { item } \\
\text { number }\end{array}$ & CS items content & $\begin{array}{c}\text { Factor } 1 \\
\text { Morning preference }\end{array}$ & $\begin{array}{c}\text { Factor } 2 \\
\text { Morning alertness }\end{array}$ & $\begin{array}{c}\text { Factor } 3 \\
\text { Evening tiredness }\end{array}$ \\
\hline 11 & Difficulty to rise at $6: 00$ a.m. & 0.771 & 0.615 & 0.400 \\
\hline 10 & Time preferred to rise for a full day's work & 0.752 & 0.432 & 0.340 \\
\hline 9 & Self-classification/assessment as morning or evening type & 0.741 & 0.466 & 0.478 \\
\hline 13 & Level of morning or evening active individual & 0.719 & 0.465 & 0.492 \\
\hline 1 & Time preferred to get up in morning & 0.698 & 0.260 & 0.313 \\
\hline 6 & Physical exercise between 7:00-8:00 a.m. & 0.582 & 0.470 & 0.042 \\
\hline 8 & Time of preferred peak performance for a test & 0.554 & 0.101 & 0.146 \\
\hline 4 & The degree of alertness during the first half hour after waking up & 0.344 & 0.860 & 0.165 \\
\hline 5 & The degree of tiredness during the first half hour after waking up & 0.339 & 0.815 & 0.159 \\
\hline 3 & Ease of getting up in the morning & 0.453 & 0.730 & 0.200 \\
\hline 12 & Time for recovery after rising from a night's sleep & 0.520 & 0.529 & 0.113 \\
\hline 7 & Time when one feels tired in the evening as a need of sleep & 0.378 & 0.184 & 0.885 \\
\hline 2 & Preferred time to go to bed in the evening & 0.315 & 0.182 & 0.884 \\
\hline \multicolumn{2}{|c|}{ Initial eigenvalues } & 4.88 & 1.61 & 1.13 \\
\hline \multicolumn{2}{|c|}{ Eigenvalues after rotation } & 4.31 & 3.58 & 2.54 \\
\hline \multicolumn{2}{|c|}{ Variance (\%) } & 37.5 & 12.3 & 8.6 \\
\hline \multicolumn{2}{|c|}{ Component correlation } & Morning preference & Morning alertness & Evening tiredness \\
\hline \multicolumn{2}{|c|}{ Morning preference } & 1.00 & 0.54 & 0.43 \\
\hline \multicolumn{2}{|c|}{ Morning alertness } & 0.54 & 1.00 & 0.24 \\
\hline \multicolumn{2}{|c|}{ Evening tiredness } & 0.43 & 0.24 & 1.00 \\
\hline
\end{tabular}

Promax rotation was performed.

CS, Korean translation of composite scale of morningness.

Table 3. CS difference among BPD1, BPD2, and MDDR: male and female

\begin{tabular}{|c|c|c|c|c|c|c|c|}
\hline & \multirow{2}{*}{$\begin{array}{c}\text { BPD1 } \\
\text { Mean (SD) }\end{array}$} & \multirow{2}{*}{$\begin{array}{c}\text { BPD2 } \\
\text { Mean (SD) }\end{array}$} & \multirow{2}{*}{$\begin{array}{c}\text { MDDR } \\
\text { Mean (SD) }\end{array}$} & \multirow{2}{*}{$\mathrm{F}$} & \multirow{2}{*}{$p$ value } & \multicolumn{2}{|c|}{ Group comparison } \\
\hline & & & & & & & $p$ value \\
\hline 1 & $3.35(1.20)$ & $3.12(1.33)$ & $3.78(1.15)$ & 0.710 & 0.493 & & \\
\hline 2 & $3.04(1.00)$ & $2.44(0.98)$ & $3.24(0.73)$ & 4.769 & 0.009 & BPD1 > BPD2 & 0.007 \\
\hline 3 & $2.39(0.89)$ & $2.30(0.67)$ & $2.39(0.89)$ & 0.404 & 0.668 & & \\
\hline 4 & $2.16(0.76)$ & $2.05(0.69)$ & $2.00(0.85)$ & 2.232 & 0.109 & & \\
\hline 5 & $2.61(0.78)$ & $2.33(0.78)$ & $2.31(0.86)$ & 6.144 & 0.002 & $\mathrm{BPD} 1>\mathrm{MDDR}$ & 0.002 \\
\hline 6 & $2.70(0.90)$ & $2.63(0.93)$ & $2.62(0.77)$ & 0.253 & 0.777 & & \\
\hline 7 & $2.97(0.99)$ & $2.67(0.92)$ & $3.32(0.86)$ & 1.291 & 0.277 & & \\
\hline 8 & $2.62(0.97)$ & $2.53(0.91)$ & $2.87(0.93)$ & 0.964 & 0.383 & & \\
\hline 9 & $2.03(1.02)$ & $1.89(0.85)$ & $2.58(1.08)$ & 2.946 & 0.054 & & \\
\hline 10 & $1.94(1.10)$ & $1.88(0.88)$ & $2.15(1.13)$ & 0.293 & 0.747 & & \\
\hline 11 & $2.38(1.09)$ & $2.28(1.00)$ & $2.66(1.03)$ & 0.017 & 0.983 & & \\
\hline 12 & $3.00(0.96)$ & $2.93(1.00)$ & $2.93(1.08)$ & 0.752 & 0.472 & & \\
\hline 13 & $2.24(1.02)$ & $1.98(0.96)$ & $2.59(1.03)$ & 1.093 & 0.337 & & \\
\hline Total score & $33.42(7.92)$ & $31.02(7.45)$ & $35.44(7.26)$ & 0.721 & 0.487 & & \\
\hline Factor 1 & $-0.14(0.98)$ & $-0.29(0.97)$ & $0.25(0.98)$ & 0.550 & 0.578 & & \\
\hline Factor 2 & $0.12(0.95)$ & $-0.10(0.91)$ & $-0.08(1.08)$ & 3.308 & 0.038 & BPDI > MDDR & 0.034 \\
\hline Factor 3 & $-0.09(1.06)$ & $-0.60(1.02)$ & $0.32(0.80)$ & 3.050 & 0.049 & BPD1 > BPD2 & 0.060 \\
\hline
\end{tabular}

Factor 1: morning preference, factor 2: morning alertness, factor 3: evening tiredness.

In case of significant difference among three diagnostic groups (BPD1, BPD2 and MDDR), post hoc comparisons were performed. CS, Korean translation of composite scale of morningness; BPD1, bipolar I disorder; BPD2, bipolar II disorder; MDDR, major depressive disorder, recurrent; SD, standard deviation.

$p<0.001$ ), and scores of two factors of CS were also significantly correlated with the age at interview in all the subjects (morning preference: Pearson's $\mathrm{r}=0.265, p<$ 0.001; evening tiredness: Pearson's $\mathrm{r}=0.388, p<0.001$ ).

CS scores for each diagnostic group are presented in Table 3. There was no significant difference in CS total score among the three groups. However there were significant differences in the factor scores of CS among the three groups. BPD1 subjects had a higher score of evening tiredness than BPD2 subjects (BPD1, $-0.09>$ BPD2, $-0.60 ; p=0.060)$. BPD1 subjects had a significantly higher mean score than MDDR subjects in morning alertness 
(BPD1, 0.12>MDDR, $-0.08 ; p=0.034)$. There were significant differences in specific individual item scores on $\mathrm{CS}$ among the three groups. There was a significant difference in the mean scores of item 2 (preferred time to go to bed in the evening) of the evening tiredness factor between BPD1 and BPD2 (BPD1, 3.04>BPD2, 2.44; $p=0.007$ ). The mean score of item 5 (the degree of tiredness during the first half hour after waking up), a morning alertness factor, was significantly different between BPD1 and MDDR (BPD1, 2.61 > MDDR, 2.31; $p=0.002$ ) (Table 3 ). This difference was slightly more profound in the female subgroup than in the male subgroup (data not shown).

\section{DISCUSSION}

We found that circadian rhythm characteristics were different among mood disorders in this sample. BPD2 patients were more likely to experience evening tiredness than BPD1 patients and MDDR patients had less morning alertness than those with BPD1.

The correlation between age and CS was that older individuals tended towards morningness. ${ }^{4)}$ Children seemed to tend to morningness, but with age, the preferred time became progressively later, reaching a maximum in lateness at around 20 years of age, and then become earlier again with increasing age. ${ }^{38)}$ In our sample, total scores and the scores on morning preference and evening tiredness were also significantly correlated with age in the whole study population (data not shown).

In our study, individuals with BPD2 obtained lower scores than did those with BPD1 on all CS scales. Although the differences for total, factor and item scores did not reach statistical significance (except item 2), the tendency seemed clear. These data suggest that eveningness features are more highly associated with BPD2 than with BPD1. There have been studies showing evidence that BPD2 is different from BPD1, and that BPD2 is clinically even more complicated than BPD1 in many aspects. BPD2 patients experience longer depressive episodes, and more persistent residual depressive symptoms than BPD1 patients. ${ }^{39)}$ BPD2 patients spent a greater proportion of time in partial remission, and less time in full remission, though BPD1 patients had more severe episodes. $^{31,40)}$ Depressive symptoms at syndromal or subsyndromal levels appear to be strongly associated with poor psychosocial functioning in BPD. ${ }^{19,41)}$ Additionally, it has been demonstrated that BPD2 patients exhibited a higher prevalence of premenstrual symptoms than the control individuals unlike BPD1. ${ }^{42)}$ These suggest that BPD1 and BPD2 are sufficiently distinct in terms of long-term course and distinctive subtypes with different clinical characteristics. The course of illness in BPD2 patients seems to be more chronic and less episodic. These findings provide strong support for the notion that BPD2 is more highly correlated with the eveningness characteristics of the circadian rhythm.

In this study, we found that patients with MDDR were less morning alertness than those with BPD1. However, individuals with MDDR obtained higher scores than did those with BPD1 on in the CS items (except item 6) corresponding with morning preference and evening tiredness factors. Although these differences for the total, factor and item scores did not reach statistical significance (except morning alertness factor scores and item 5), the tendency seemed clear. Our results suggest that more MDDR patients are subjectively tired in the morning than BPD1 patients. From this finding, it is reasonable to assume that individuals with MDDR resemble individuals with BPD2 in $\mathrm{M} / \mathrm{E}$. One possible explanation for this finding would be that MDDR patients seemed to be chronically ill like BPD2 patients. In addition, MDDR is a heterogeneous diagnosis on the current DSM-IV diagnostic criteria. It includes a diagnostic specifier for hidden bipolarity in MDD, emerging evidence for a conceptualization of hypomanic symptoms has been proposed. ${ }^{43)}$ The current DSM-IV diagnostic criteria for BPD2 fail to include milder but clinically significant bipolar syndromes. A significant percentage of these conditions are diagnosed by default on MDD criteria as chronic MDD or MDDR. ${ }^{44-46)}$ It is possible that some MDD patients have significant subclinical bipolarity. These results show that MDDR and BPD2 have similar characteristics with their clinical correlates.

Several limitations of this study should be noted. First, CS is a self-rating scale and scoring is based on subjective evaluations. Although patients were clinically stable, subsyndromal mood symptoms can also affect the subjects' attitude toward their own characteristics. However, we carefully selected for euthymic patients by assessing current mood status. Second, the relatively small sample size, and the differences among diagnostic groups in number of subjects and gender distribution means the study lacks sufficient statistical power. In particular, the BPD2 group consisted of only 41 subjects. This could reflect the relative rarity of diagnosis of BPD2 in clinical practice. It is suggested that BPD2 patients may present with different mood disorders such as dysthymic disorder or MDD de- 
pending on the age of interview. ${ }^{47)}$ Third, we conducted multiple comparisons (i.e., CS factor-wise, CS item-wise, and gender-wise) to verify several possibilities about the complex features of CS among different mood disorders. However, the $p$ values in this study were not corrected for multiple testing. This should be considered during interpretation of the results. Fourth, our sample was composed of only three diagnostic groups, and there was no control group. Therefore BPD patients could not be compared with screened control individuals like previous studies. ${ }^{28-30)}$ Further studies including collection of control subjects and additional analyses should be undertaken to explore this area further.

We used the CS total score, factor scores, and individual item scores to measure $\mathrm{M} / \mathrm{E}$ features. In the present study, there were also no significant differences in the CS total scores between BPD1 or BPD2 patients. This result was consistent with that of a previous study. ${ }^{29)}$ Because CS addresses the complex features of the circadian rhythm, scores on three factors and scores on individual items were applied in further analysis. Especially item 2 seems to be representative for the factor of evening tiredness and item 5 seems to be representative for the factor of morning alertness. These items were found to be even more sensitive in catching differences between the disease groups.

It has been suggested that circadian rhythm characteristics could be an endophenotype of mood disorders. Endonphenotype is considered as a helpful link to find genes for disease because it is less complex in phenotypic manifestation and more likely to be controlled by small number of genes. ${ }^{48)}$ Especially for the BPD, circadian rhythm instability on sleep-wake cycle, body temperature and neuroendocrine profiles found to be associated. ${ }^{10,49,50)}$ Lithium's therapeutic effect on BPD might be brought from the lithium's effect on circadian cycles. ${ }^{51)}$ In this study, we found different CS factor scores among mood disorders. Taken all together, it is possible that CS, a stable and quantifiable measure reflecting circadian rhythm, would be a reasonable endophenotype associated with mood disorder. Investigations on genetic eiologies of mood disorder using CS endophenotype could be promising.

In conclusion, we found that different mood disorders had different circadian rhythm characteristics through comparing the factor scores and specific item scores of CS among BPD1, BPD2 and MDDR. BPD2 showed more eveningness than BPD1, and MDDR showed less morningness than BPD1. CS would be a reasonable endophenotype associated with mood disorders. More studies with large sample size of mood disorder on $\mathrm{M} / \mathrm{E}$ are warranted.

\section{Acknowledgments}

This work was supported by National Research Foundation of Korea Grant funded by the Korean Government (KRF-2008-531-E00045 and 2011-0003164).

\section{REFERENCES}

1. Duffy JF, Rimmer DW, Czeisler CA. Association of intrinsic circadian period with morningness-eveningness, usual wake time, and circadian phase. Behav Neurosci 2001;115: 895-899.

2. Horne JA, Ostberg O. A self-assessment questionnaire to determine morningness-eveningness in human circadian rhythms. Int J Chronobiol 1976;4:97-110.

3. Nebel LE, Howell RH, Krantz DS, Falconer JJ, Gottdiener JS, Gabbay FH. The circadian variation of cardiovascular stress levels and reactivity: relationship to individual differences in morningness/eveningness. Psychophysiology 1996;33:273-281.

4. Baehr EK, Revelle W, Eastman CI. Individual differences in the phase and amplitude of the human circadian temperature rhythm: with an emphasis on morningness-eveningness. J Sleep Res 2000;9:117-127.

5. Amorim P, Lecrubier Y, Weiller E, Hergueta T, Sheehan D. DSM-IH-R psychotic disorders: procedural validity of the Mini International Neuropsychiatric Interview (MINI). Concordance and causes for discordance with the CIDI. Eur Psychiatry 1998;13:26-34.

6. Katzenberg D, Young T, Finn L, Lin L, King DP, Takahashi $\mathrm{JS}$, et al. A CLOCK polymorphism associated with human diurnal preference. Sleep 1998;21:569-576.

7. Mishima K, Tozawa T, Satoh K, Saitoh H, Mishima Y. The $3111 T / C$ polymorphism of hClock is associated with evening preference and delayed sleep timing in a Japanese population sample. Am J Med Genet B Neuropsychiatr Genet 2005;133B:101-104.

8. Takahashi JS, Hong HK, Ko $\mathrm{CH}$, McDearmon EL. The genetics of mammalian circadian order and disorder: implications for physiology and disease. Nat Rev Genet 2008; 9:764-775.

9. Harvey AG. Sleep and circadian rhythms in bipolar disorder: seeking synchrony, harmony, and regulation. Am J Psychiatry 2008; 165:820-829.

10. Jackson A, Cavanagh J, Scott J. A systematic review of manic and depressive prodromes. J Affect Disord 2003;74:209-217.

11. Wirz-Justice A. Biological rhythm disturbances in mood disorders. Int Clin Psychopharmacol 2006;21(Suppl 1):S11-S15.

12. Knowles JB, Cairns J, MacLean AW, Delva N, Prowse A, Waldron $\mathrm{J}$, et al. The sleep of remitted bipolar depressives: comparison with sex and age-matched controls. Can J Psychiatry 1986;31:295-298.

13. Millar A, Espie CA, Scott J. The sleep of remitted bipolar outpatients: a controlled naturalistic study using actigraphy. J Affect Disord 2004;80:145-153.

14. Jones SH, Hare DJ, Evershed K. Actigraphic assessment of circadian activity and sleep patterns in bipolar disorder. Bipolar Disord 2005;7:176-186.

15. Monteleone P, Maj M. The circadian basis of mood disorders: recent developments and treatment implications. Eur Neuropsychopharmacol 2008;18:701-711.

16. Goodwin GM; Consensus Group of the British Association 
for Psychopharmacology. Evidence-based guidelines for treating bipolar disorder: revised second edition-recommendations from the British Association for Psychopharmacology. J Psychopharmacol 2009;23:346-388.

17. Yatham LN, Kennedy SH, O'Donovan C, Parikh SV, MacQueen G, McIntyre RS, et al; Guidelines Group, CANMAT. Canadian Network for Mood and Anxiety Treatments (CANMAT) guidelines for the management of patients with bipolar disorder: update 2007. Bipolar Disord 2006;8:721-739.

18. Nurnberger JI Jr, Adkins S, Lahiri DK, Mayeda A, Hu K, Lewy A, et al. Melatonin suppression by light in euthymic bipolar and unipolar patients. Arch Gen Psychiatry 2000; 57:572-579.

19. Simon GE, Bauer MS, Ludman EJ, Operskalski BH, Unützer J. Mood symptoms, functional impairment, and disability in people with bipolar disorder: specific effects of mania and depression. J Clin Psychiatry 2007;68:1237-1245.

20. Grandin LD, Alloy LB, Abramson LY. The social zeitgeber theory, circadian rhythms, and mood disorders: review and evaluation. Clin Psychol Rev 2006;26:679-694.

21. Lenox RH, Gould TD, Manji HK. Endophenotypes in bipolar disorder. Am J Med Genet 2002;114:391-406.

22. Benedetti F, Radaelli D, Bernasconi A, Dallaspezia S, Falini $\mathrm{A}$, Scotti G, et al. Clock genes beyond the clock: CLOCK genotype biases neural correlates of moral valence decision in depressed patients. Genes Brain Behav 2008;7:20-25.

23. Roybal K, Theobold D, Graham A, DiNieri JA, Russo SJ, Krishnan V, et al. Mania-like behavior induced by disruption of CLOCK. Proc Natl Acad Sci USA 2007; 104:6406-6411.

24. Desan PH, Oren DA, Malison R, Price LH, Rosenbaum J, Smoller J, et al. Genetic polymorphism at the CLOCK gene locus and major depression. Am J Med Genet 2000;96: 418-421.

25. Chelminski I, Ferraro FR, Petros TV, Plaud JJ. An analysis of the "eveningness-morningness" dimension in "depressive" college students. J Affect Disord 1999;52:19-29.

26. Caci H, Adan A, Bohle P, Natale V, Pornpitakpan C, Tilley A. Transcultural properties of the composite scale of morningness: the relevance of the "morning affect" factor. Chronobiol Int 2005;22:523-540.

27. Drennan MD, Klauber MR, Kripke DF, Goyette LM. The effects of depression and age on the Horne-Ostberg morningness-eveningness score. J Affect Disord 1991;23:93-98.

28. Mansour HA, Wood J, Chowdari KV, Dayal M, Thase ME, Kupfer DJ, et al. Circadian phase variation in bipolar I disorder. Chronobiol Int 2005;22:571-584.

29. Wood J, Birmaher B, Axelson D, Ehmann M, Kalas C, Monk $\mathrm{K}$, et al. Replicable differences in preferred circadian phase between bipolar disorder patients and control individuals. Psychiatry Res 2009;166:201-209.

30. Ahn YM, Chang J, Joo YH, Kim SC, Lee KY, Kim YS Chronotype distribution in bipolar I disorder and schizophrenia in a Korean sample. Bipolar Disord 2008;10:271-275.

31. Judd LL, Akiskal HS, Schettler PJ, Coryell W, Maser J, Rice $\mathrm{JA}$, et al. The comparative clinical phenotype and long term longitudinal episode course of bipolar I and II: a clinical spectrum or distinct disorders? J Affect Disord 2003;73:19-32.

32. Yoo SW, Kim YS, Noh JS, Oh KS, Kim CH, Namkoong $\mathrm{K}$, et al. Validity of Korean version of the mini-international neuropsychiatric interview. Anxiety Mood 2006;2:50-55.

33. Smith CS, Reilly C, Midkiff K. Evaluation of three circadian rhythm questionnaires with suggestions for an improved measure of morningness. J Appl Psychol 1989;74:728-738.

34. Greenwood KM. Long-term stability and psychometric properties of the composite scale of morningness. Ergonomics 1994:37:377-383.

35. Caci $\mathrm{H}$, Nadalet L, Staccini $\mathrm{P}$, Myquel M, Boyer P. The composite scale of morningness: further psychometric properties and temporal stability. Eur Psychiatry 2000;15:278281.

36. Yoon JS, Shin SM, Kook SH, Lee HY. A preliminary study on the Korean translation of composite scale(KtCS) to measure morningness: eveningness. J Korean Neuropsychiatr Assoc 1997;36:122-134.

37. Kook SH, Yoon JS, Lee HY. Cross validation of the Korean translation of composite scale(KtCS) to measure morningnesseveningness. J Korean Neuropsychiatr Assoc 1999;38:297305.

38. Roenneberg T, Kuehnle T, Pramstaller PP, Ricken J, Havel $\mathrm{M}$, Guth A, et al. A marker for the end of adolescence. Curr Biol 2004;14:R1038-R1039.

39. Benazzi F. Course and outcome of bipolar II disorder: a retrospective study. Psychiatry Clin Neurosci 2001;55:67-70.

40. Mantere O, Suominen K, Valtonen HM, Arvilommi P, Leppämäki S, Melartin T, et al. Differences in outcome of DSM-IV bipolar I and II disorders. Bipolar Disord 2008; 10:413-425.

41. Simon GE, Ludman EJ, Unützer J, Operskalski BH, Bauer MS. Severity of mood symptoms and work productivity in people treated for bipolar disorder. Bipolar Disord 2008;10: 718-725.

42. Choi J, Baek JH, Noh J, Kim JS, Choi JS, Ha K, et al. Association of seasonality and premenstrual symptoms in bipolar I and bipolar II disorders. J Affect Disord 2011;129: 313-316.

43. Angst J. The bipolar spectrum. Br J Psychiatry 2007;190: 189-191.

44. Zimmermann P, Brückl T, Nocon A, Pfister H, Lieb R, Wittchen $\mathrm{HU}$, et al. Heterogeneity of DSM-IV major depressive disorder as a consequence of subthreshold bipolarity. Arch Gen Psychiatry 2009;66:1341-1352.

45. Judd LL, Akiskal HS. The prevalence and disability of bipolar spectrum disorders in the US population: re-analysis of the ECA database taking into account subthreshold cases. J Affect Disord 2003;73:123-131.

46. Angst J, Cui L, Swendsen J, Rothen S, Cravchik A, Kessler $\mathrm{RC}$, et al. Major depressive disorder with subthreshold bipolarity in the National Comorbidity Survey Replication. Am J Psychiatry 2010;167:1194-1201.

47. Kim W, Woo YS, Chae JH, Bahk WM. The diagnostic stability of DSM-IV diagnoses: An examination of major depressive disorder, bipolar I disorder, and schizophrenia in Korean patients. Clin Psychopharmacol Neurosci 2011;9: 117-121.

48. Hasler G, Drevets WC, Gould TD, Gottesman II, Manji HK. Toward constructing an endophenotype strategy for bipolar disorders. Biol Psychiatry 2006;60:93-105.

49. Linkowski P. Neuroendocrine profiles in mood disorders. Int J Neuropsychopharmacol 2003;6:191-197.

50. Souetre E, Salvati E, Wehr TA, Sack DA, Krebs B, Darcourt G. Twenty-four-hour profiles of body temperature and plasma TSH in bipolar patients during depression and during remission and in normal control subjects. Am J Psychiatry 1988;145:1133-1137.

51. Gould TD, Manji HK. The Wnt signaling pathway in bipolar disorder. Neuroscientist 2002;8:497-511. 